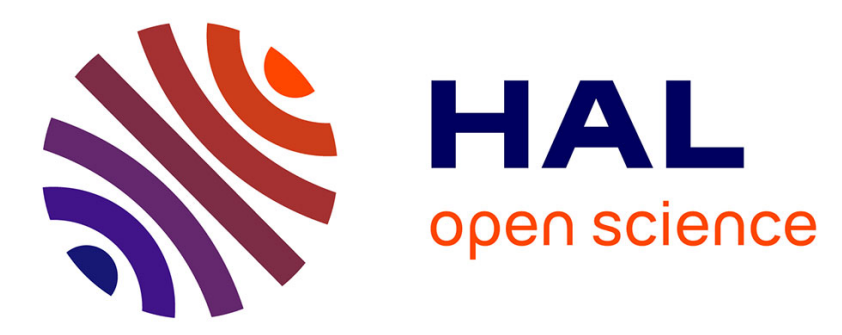

\title{
Design of gold nanoshells via a gelatin-mediated self-assembly of gold nanoparticles on silica cores
}

Joachim Allouche, Samantha Soulé, Jean-Charles Dupin, Sylvie Masse, T. Coradin, Hervé Martinez

\section{- To cite this version:}

Joachim Allouche, Samantha Soulé, Jean-Charles Dupin, Sylvie Masse, T. Coradin, et al.. Design of gold nanoshells via a gelatin-mediated self-assembly of gold nanoparticles on silica cores. RSC Advances, 2014, 4 (108), pp.63234-63237. 10.1039/C4RA13793K . hal-01137803

\section{HAL Id: hal-01137803 https://hal.sorbonne-universite.fr/hal-01137803}

Submitted on 31 Mar 2015

HAL is a multi-disciplinary open access archive for the deposit and dissemination of scientific research documents, whether they are published or not. The documents may come from teaching and research institutions in France or abroad, or from public or private research centers.
L'archive ouverte pluridisciplinaire HAL, est destinée au dépôt et à la diffusion de documents scientifiques de niveau recherche, publiés ou non, émanant des établissements d'enseignement et de recherche français ou étrangers, des laboratoires publics ou privés. 


\title{
Design of gold nanoshells via a gelatin-mediated gold nanoparticles self-assembly on silica core.
}

\author{
Joachim Allouche, ${ }^{a *}$ Samantha Soulé, ${ }^{a}$ Jean-Charles Dupin, ${ }^{a}$ Sylvie Masse, ${ }^{b}$ \\ Thibaud Coradin, ${ }^{b}$ and Hervé Martinez. ${ }^{a}$
}

A gelatin-mediated gold nanoparticles self-assembly has been performed on silica particles during gold ions reduction using ascorbic acid as reductant and PVP as stabilizer. Gold nanoshells with near infrared photothermal properties have been successfully designed.

In the past decades, gold based nanomaterials have undergone an important development and intensive investigations due to their unique optical properties coming from a so-called Surface Plasmon Resonance (SPR) phenomenon. ${ }^{1-3}$ Such properties combined to gold biocompatibility have found a great interest particularly in biomedical applications with the rising of Nanomedicine $e^{4,5}$ and development of Theranostic agents. ${ }^{6,7}$ Until now, a multitude of gold plasmonic nanostructures have been described including nanospheres, ${ }^{8}$ nanorods, ${ }^{9,10}$ nanorice, ${ }^{11}$ nanorings, ${ }^{12}$ nanocages, ${ }^{13}$ nanoshells ${ }^{14,15}$ and so forth for which their dimensions and morphologies allow to modulate the SPR features in a wide absorption range from UV-Vis region to infrared region. In particular, gold nanoshells (GNS) have attracted a great attention in the past years due to their absorption in such Near Infrared Region (NIR) also called "biological window" where human tissues are transparent to light. ${ }^{14}$ Such optical properties of GNS have found applications in cancer photothermal therapy where localized ablation of tumor cells is performed via near infrared laser irradiation. ${ }^{16,17}$ On the other hand, in the field of the design of gold nanostructures, a great effort is nowadays done on the control of assembly and aggregation of gold nanomaterials in order to generate $2 \mathrm{D}$ or $3 \mathrm{D}$ architectures mainly for molecular recognition, biosensing or bioanalytical assays ${ }^{18,19}$ using organic linkers, ${ }^{20-22}$ polymers or biopolymers..$^{23}$ In the latter case, several macromolecules including DNA, ${ }^{24}$ chitosan $^{25-27}$ or proteins ${ }^{28-30}$ have been successfully conjugated to gold nanoparticles to drive a specific organization. In this context, gelatin is particularly attractive for the design of gold nanostructure due to its good biocompatibility, capping properties and ability to reduce gold ions..$^{31,32}$ We demonstrate here for the first time that gelatin can be successfully used as mediator of gold nanoparticles self-assembly on silica particles in order to generate GNS. Indeed, gelatin is known to strongly interact with silica through electrostatic interactions $\mathrm{s}^{33-35}$ and is able to bond noble metals via amino or carboxylate groups. ${ }^{36}$ Taking advantage of these dual properties, a GNS synthesis method based on ascorbic acid mediated gold ions reduction in presence of gelatin-modified silica particles (NPSiGel) is described. Our approach could be purposed as an alternative to the main known gold nanoshell elaboration methods described elsewhere e.g. (i) the galvanic replacement process ${ }^{14}$ and (ii) the two steps seed-growth method. ${ }^{15}$ Indeed, the main advantages of our approach comparing to the latter ones lie in the formation of the gold shell without a seeding step and without a preliminary synthesis of metal (e.g. silver or cobalt) gabarit particles that generally results in the formation of alloys. ${ }^{37,38}$

Our synthetic procedure is described as follow: silica nanoparticles (NPSi) were first elaborated via a typical Stöber process $^{39}$ in an ethanol/water solution using tetraorthosilicate (TEOS) as silica source and ammonium hydroxide as catalyzer. The molar ratio TEOS : Water : Ethanol : Ammonia was $1: 19.2$ : $63.7: 1.1$. Twenty milliliters of the obtained silica particles were washed several times and a gelatin (Type A from porcine skin, 300 Bloom, Aldrich) coating has been performed in $1 \mathrm{wt}$ \% of biopolymer aqueous solution at $40{ }^{\circ} \mathrm{C}$ to provide silica/gelatin nanoparticles (NPSiGel). After several cycles of centrifugation/washing, samples of gold coating on NPSiGel were carried out as follow: $0.08 \mathrm{~g}$ of PVP (Polyvinylpyrrolidone, Aldrich, $50000 \mathrm{~g} / \mathrm{mol}$ ) was first dissolved in $15 \mathrm{ml}$ of deionised water before pouring $0.005 \mathrm{~g}$ of ASA (Ascorbic Acid, Aldrich). The solution was stirred until complete dissolution of ASA. Then, $25 \mu$ l of NPSiGel solution was poured in the previous solution. After 30s of agitation, $x$ $=0.25,0.5,1,2,3$ or $4 \mathrm{ml}$ of a $0.2 \mathrm{wt} . \%$ chloroauric solution ( $\mathrm{HAuCl}_{4} .3 \mathrm{H}_{2} \mathrm{O}$, Aldrich) was added in the previous solution under 600 rpm magnetic stirring giving gold concentrations of 1.3, 2.5, 5, 10, 15 or $20 \mathrm{mM}$ respectively. For $\mathrm{x} \leq 1 \mathrm{ml}$, the gold solution was injected at only one go. For $x>1 \mathrm{ml}$, aliquots of $1 \mathrm{ml}$ were added every $5 \mathrm{~s}$. After 
ch addition, the color of the solution evolves extremely quickly within a few seconds. The final color of the gold particle solution is attained after 30 s after the last aliquot addition and varied from light pink to deep blue depending on the gold amount added. The solutions were stirred $2 \mathrm{~min}$ before washing and material characterizations by Transmission Electron Microscopy (TEM), Scanning Electron Microscopy (SEM), X-ray Photoelectron Spectroscopy (XPS), X-Ray Diffraction (XRD) and UV-Vis spectroscopy. On the basis of microscopic observations, the average diameter of NPSiGel (Fig. 1a) was evaluated to $70 \pm 10 \mathrm{~nm}$.

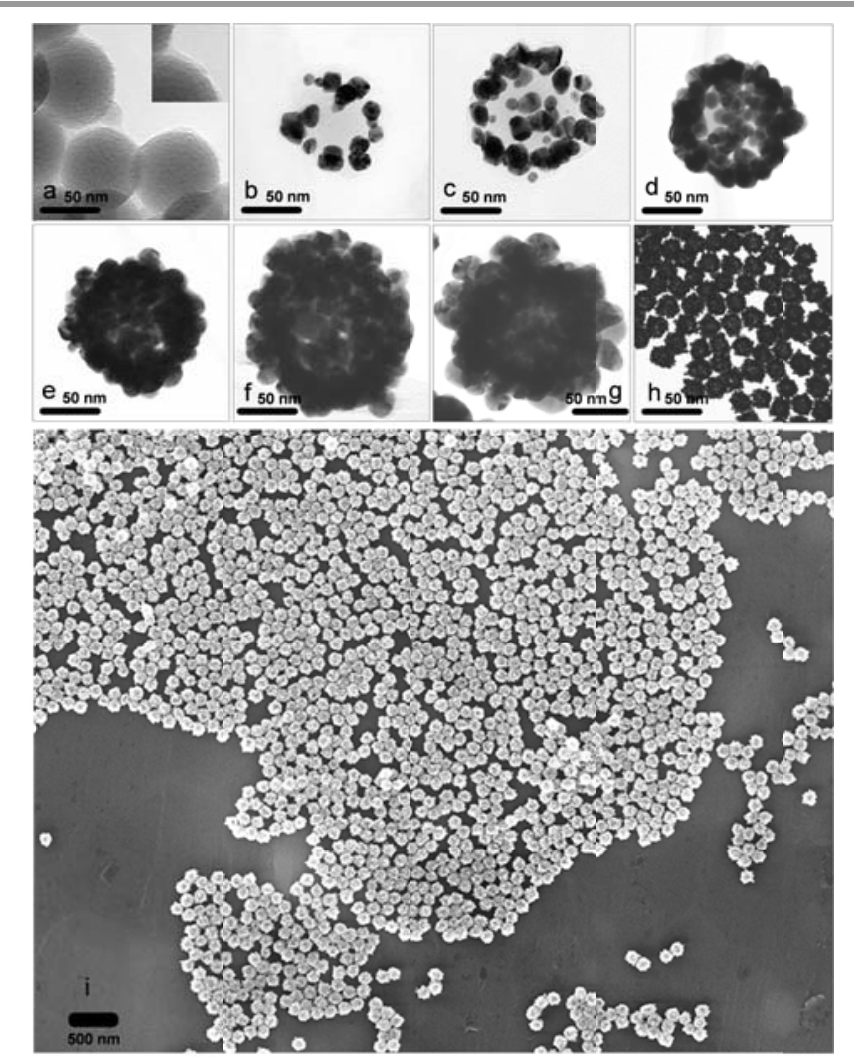

Fig. 1. TEM (from a to h) and SEM (only i) images of gold coating on silica/gelatin NPSiGel nanoparticles in function of the concentration of chloroauric solution (corresponding to $x \mathrm{ml}$ of gold ions solution added): (a) $0(x=0 \mathrm{ml})$; (b) $1.3 \mathrm{mM}$ $(x=0.25 \mathrm{ml})$; (c) $2.5 \mathrm{mM}(\mathrm{x}=0.5 \mathrm{ml})$; (d) $5 \mathrm{mM}$ ( $\mathrm{x}=1 \mathrm{ml})$; (e) $10 \mathrm{mM}(\mathrm{x}=2 \mathrm{ml})$; (f) $15 \mathrm{mM}(\mathrm{x}=3 \mathrm{ml})$; (g), (h) and (i) $20 \mathrm{mM}(\mathrm{x}=4 \mathrm{ml})$.

As shown on the inset of Fig. 1 a, a thin gelatin layer on NPSiGel $(\approx 1.5$ $\pm 1 \mathrm{~nm}$ ) is clearly identifiable. As the amount of gold precursor added increases (Fig. 1b to 1i), gold metal deposition on NPSiGel rises until a complete gold coverage is attained for $x=4 \mathrm{ml}$. The evolution of such gold coating is accompanied by an increase in the average diameter of the whole core-shell system from $80 \pm 10 \mathrm{~nm}$ (Fig. 1b) to $170 \pm 20 \mathrm{~nm}$ (low (Fig. 1g) and high (Fig. 1h and 1i) magnification). In addition, it is worth noting that the gold shell is composed of agglomerated and self-assembled gold nanoparticles on NPSiGel core. At low gold amount added $(x=0.25 \mathrm{ml}$ and $x=0.5 \mathrm{ml}$ ), gold nanoparticles of $10 \pm 5 \mathrm{~nm}$ to $20 \pm 5 \mathrm{~nm}$ in diameter are clearly seen on NPSiGel. As gold concentration increases, the deposition of gold nanoparticles rises until gold nanoshell is formed. We have noticed on TEM images that at high gold amount added ( $x=3$ and $4 \mathrm{ml}$ ), diameters of gold nanoparticles are slightly higher (between $20 \pm 5$ $\mathrm{nm}$ and $35 \pm 5 \mathrm{~nm}$ ) than for low gold concentration indicating that a growth step occurred during latest gold precursor additions.

XRD pattern (ESI, + Fig. S1) of GNS with highest gold concentration $(20 \mathrm{mM})$ confirms the crystalline nature of gold nanoparticles. All Bragg reflections have been distinctly indexed to a face-centered cubic (fcc) phase and the lattice parameter $\mathrm{a}=4.0785 \AA$ which is consistent with the standard data files (JCPDS no. 03-065-2870). Below $30^{\circ}$, broader peaks are attributed to amorphous silica and organic components. The gold crystallite size estimated from XRD pattern using Scherrer's equation is $10 \mathrm{~nm}$ which is smaller than that measured by TEM images suggesting that gold nanoparticles are polycrystalline.

To complete the previous results, XPS experiments were carried out for each step of the synthesis. First, the gelatin coating on silica nanoparticles was confirmed by the C1s spectrum of NPSiGel (ESI, + Fig. S2a) that evidences the two characteristic C-N bond components in amine and amide groups of gelatin at $286.3 \mathrm{eV}$ and $288.1 \mathrm{eV}$ respectively. ${ }^{40}$ Moreover, the N1s feature (ESI, + Fig. S2b) corroborates this observation with the appearance of gelatin nitrogen signature on NPSiGel.

Secondly, chemical analyses were: systematically achieved for any content of gold precursor injected in the NPSiGel colloid solution. At low content (e.g. $x=0.5 \mathrm{ml}$ ), Au4f spectrum (Fig. 2b) fits into two doublets for which the main peaks are located at $83.9 \mathrm{eV}$ and $87.6 \mathrm{eV}$ (dotted line) for $A u 4 f_{7 / 2}$ and $A u 4 f_{5 / 2}$ respectively. Such peaks are assigned to bulk gold metal gold atoms. ${ }^{41}$ Besides, a broad shoulder component at lower binding energy is visible for the two doublets which is generally reported for near surface atoms emission..$^{42}$ This small surface feature is expected in the case of small nanoparticles for which surface atoms population is dominant; this is in accordance with TEM images (Fig. $1 \mathrm{~b}$ and 1c). With the increase of chloroauric solution content (e.g., $\mathrm{x}=1 \mathrm{ml}$ and $\mathrm{x}=4 \mathrm{ml}$ ) and gold nanoshell growth, this low energy contribution becomes less and less visible due to the diminution of near surface atoms influence as gold coverage rises. Additionally, as the gold coating gets important (Au4f intensity rises up), the Si2p signal of NPSiGel slightly goes down before disappearing (Fig. 2a). From this evolution, XPS quantification gives $\mathrm{Si} / \mathrm{Au}$ atomic ratio values of $1.3,0.6$ and 0 for $\mathrm{x}=0.5,1$ and $4 \mathrm{ml}$ respectively.

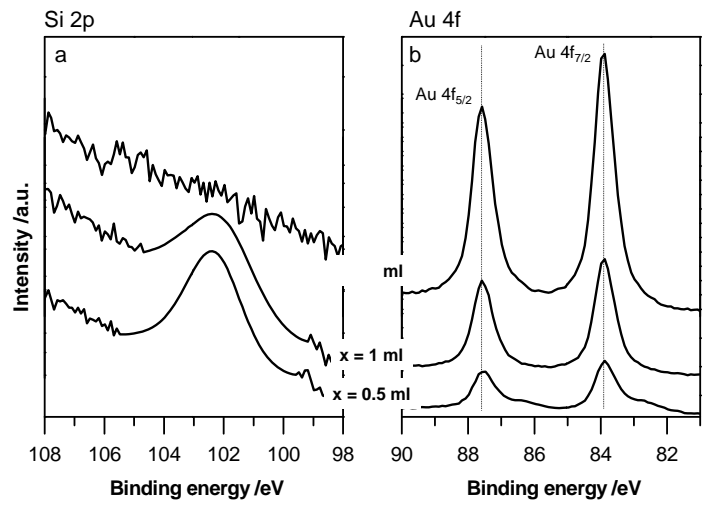

Fig. 2. XPS Si2p (a) and Au4f (b) core level spectra of gold coated NPSiGel nanoparticles for different values $\mathrm{x}=0.5,1$ and $4 \mathrm{ml}$ of gold precursor added. 
Based on these results, a mechanism of gold nanoparticles selfassembly on NPSiGel can be purpose. As described in the experimental section, gold deposition is extremely fast since the color of particle solutions does not evolves a few seconds after each gold precursor addition. On the other hand, no secondary bulk gold nucleation (outside NPSiGel particles) was identified which was confirmed by SEM analysis during the centrifugation/washing steps. These two observations are in agreement with an advantageous gold reduction at the very close vicinity of the NPSiGel particles surface. Moreover, the ASA concentration ( $1.89 \mathrm{mM}$ ) leads to a pH value of 3.6 which favors strong electrostatic interactions between negative gold ions and gelatin (IEP at $\mathrm{pH}=8-9$ ) coated silica nanoparticles. Moreover, due to the constants of dissociation of ASA (pKa, $1=4.17$, pKa, $2=11.58$ ), a majority of non-dissociated protonated form of ASA are present which promote hydrogen bonds between ASA carboxylate groups and amino gelatin groups as described for other systems. ${ }^{43}$ This favors a preferential location of ASA near NPSiGel and consequently gold reduction on NPSiGel surface while avoiding secondary bulk gold nucleation. In addition, the use of PVP stabilizer promotes gold nanoparticles formation on NPSiGel surface instead of "swallowing-like" gold growth as observed without PVP (ESI,† Fig. S3). The presence of PVP is essential to avoid strong aggregation of NPSiGel particles during gold deposition and to improve homogeneous gold coverage.

To correlate optical properties of the evolution and growth of the gold coating to the previous results, UV-Vis-NIR spectroscopy analyses were carried out. The Figure 3 overlays absorption spectra of gold coated NPSiGel particles in function of the amount of gold precursor added. The evolution of spectra exhibits a red shift as the gold coverage increases and as gold nanoparticles self-assembly and aggregation occurs at the NPSiGel surface. Such red shift is a typical feature of plasmon resonance evolution during GNS formation. ${ }^{15}$ However, different plasmonic regimes can be identified along the progressive growth of the gold layer. At low $x$ value, only one peak is observable with maxima of absorption $\left(\lambda_{\max }\right)$ centered at $559 \mathrm{~nm}$ and $565 \mathrm{~nm}$ for $\mathrm{x}=0.25 \mathrm{ml}$ and $\mathrm{x}=0.5 \mathrm{ml}$ respectively. The location of such resonance bands is similar to the one typically observed for near non aggregated $20 \mathrm{~nm}$ spherical gold nanoparticles. ${ }^{8}$ This is also associated to few immobilized gold nanoparticles on NPSiGel (see Fig. $1 \mathrm{~b}$ and Fig. 1c) leading to low plasmon-plasmon interactions between gold nanoparticles. ${ }^{20}$

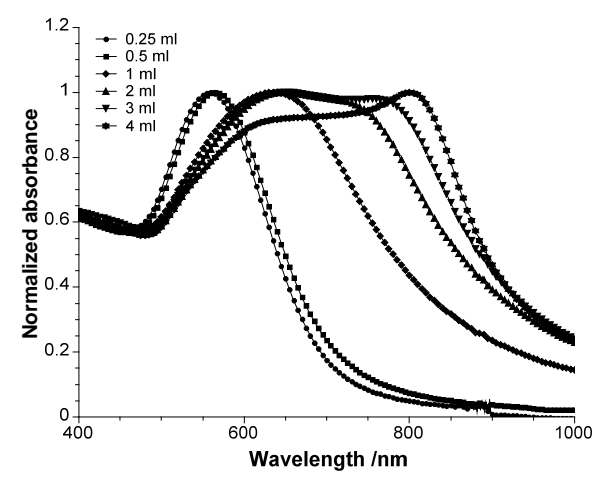

Fig. 3. Evolution of UV-Vis-NIR absorption spectra of core-shell silica/gold nanoparticles in function of the gold precursor amount added.
At intermediate $x$ value $(x=1 \mathrm{ml}$, Fig.1d), the absorption starts to undergo a significant red shift $\left(\lambda_{\max }=635 \mathrm{~nm}\right)$ with a resonance band broadening. This feature has to be put in relation with the increase of plasmon-plasmon interactions between gold nanoparticles..$^{20,44}$ For larger amounts of gold precursor ( $x=2$ and $3 \mathrm{ml}$, Fig. 1e and Fig. 1f), a higher absorption broadening occurs and is linked to the appearance of a dipole resonance mode at high wavelengths close to $800 \mathrm{~nm}$ as the gold nanoshell and hollow nanostructure is forming around NPSiGel. Such mode is concomitant to lower wavelengths resonance contribution close to $650 \mathrm{~nm}$ probably associated to the overlapping of plasmon-plasmon interactions and higher order multipole modes as described by Mie scattering theory. ${ }^{45}$ Finally, at highest gold concentration $(x=4 \mathrm{ml})$, the absorption is dominated by the dipole resonance mode of the formed GNS (peak at $\lambda_{\max }=802 \mathrm{~nm}$ ).

Laser irradiation at $808 \mathrm{~nm}$ (fiber coupled laser diode equipment, 6 $W / \mathrm{cm}^{2}, 7 \mathrm{~cm}$ from the target) was performed on such GNS with highest gold concentration $(20 \mathrm{mM})$ to valid their potentiality in terms of photothermal activity. $3 \mathrm{ml}$ of gold nanoshells solution was poured in a quartz cuvette and was irradiated through a series of 30 min laser on-off pulses under stirring. The temperature of the solution was measured in situ using a thermocouple (type $\mathrm{K}$, accuracy $= \pm 1.5^{\circ} \mathrm{C}$ ). As a comparison, irradiation experiments were also carried out on water, NPSi suspension and NPSiGel suspension at the same particles concentration than gold nanoshells. As shown on Figure 4, each irradiation period is accompanied by a temperature jump of near $25^{\circ} \mathrm{C}$ for nanoshells in comparison to a slight bump of near $3-4{ }^{\circ} \mathrm{C}$ corresponding to laser heat dissipation for water, NPSi and NPSiGel suspensions. This result demonstrates unambiguously the efficiency of the photothermal properties of the gold nanoshells.

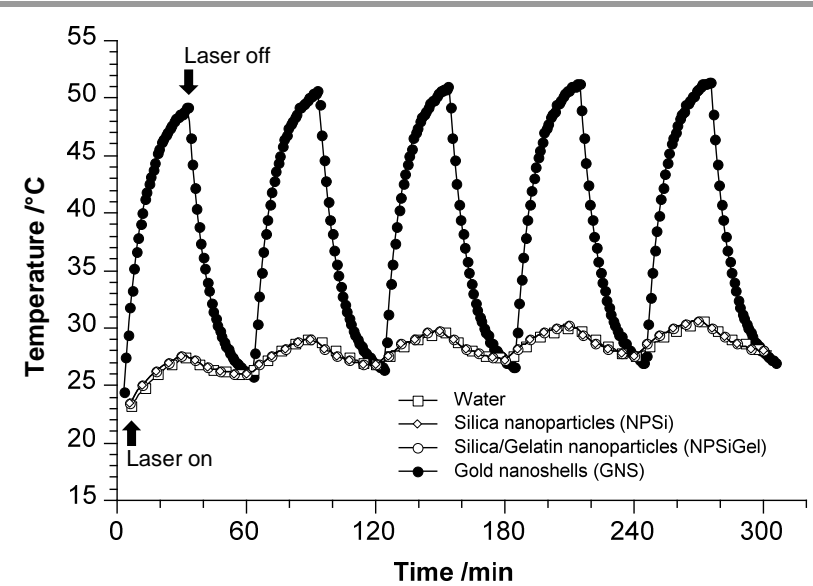

Fig. 4. Evolution of the temperature of water solution (particles free), NPSi, NPSiGel and GNS solutions during a series of $808 \mathrm{~nm} 30 \mathrm{~min}$ pulses laser irradiation.

In conclusion, we developed an original synthesis method to generate gold nanoshells through gelatin-mediated gold nanoparticles self-assembly on silica nanospheres occurring during gold ions reduction. This constitutes an alternating method to conventional galvanic replacement and seed-growth approaches previously described..$^{14,15}$ Such gold nanoshells exhibit near infrared light absorption features and present photothermal activity under laser irradiation. 


\section{Notes and references}

a Institut des Sciences Analytiques et de Physico-Chimie pour l'Environnement et les Matériaux (IPREM)-UMR5254. Equipe de Chimie Physique (ECP). Université de Pau et des Pays de l'Adour (UPPA), Technopôle Hélioparc Pau Pyrénées, 2, Avenue du Président Pierre Angot, 64053 PAU Cedex 09, France.

${ }^{\mathrm{b}}$ Chimie de la Matière Condensée de Paris, UMR 7574, Université Pierre et Marie Curie, Collège de France, 11 place Marcelin Berthelot, 75231 Paris cedex 05, France.

$\dagger$ Electronic Supplementary Information (ESI) available: XRD pattern of GNS, XPS C1s and N1s spectra of NPSiGel particles, TEM images of gold coating on silica/gelatin nanoparticles without using PVP. See DOI: $10.1039 / \mathrm{c} 000000 \mathrm{x}$

1. M.-C. Daniel and D. Astruc, Chem. Rev., 2004, 104, 293.

2. H. Wang, D. W. Brandl, P. Nordlander, and N. J. Halas, Acc. Chem. Res., 2006, 40, 53.

3. P. K. Jain, X. Huang, I. H. El-Sayed, and M. A. El-Sayed, Acc. Chem. Res., 2008, 41, 1578.

4. F. J. Robert A., Nanomedicine Nanotechnol. Biol. Med., 2005, 1, 2.

5. K. Riehemann, S. W. Schneider, T. A. Luger, B. Godin, M. Ferrari, and H. Fuchs, Angew. Chem. Int. Ed., 2009, 48, 872.

6. P. Rai, S. Mallidi, X. Zheng, R. Rahmanzadeh, Y. Mir, S. Elrington, A. Khurshid, and T. Hasan, Adv Drug Deliv Rev, 2010, 62, 1094.

7. T. Lammers, S. Aime, W. E. Hennink, G. Storm, and F. Kiessling, Acc. Chem. Res., 2011, 44, 1029.

8. M. K. Chow and C. F. Zukoski, J. Colloid Interface Sci., 1994, 165, 97.

9. C. J. Johnson, E. Dujardin, S. A. Davis, C. J. Murphy, and S. Mann, J Mater Chem, 2002, 12, 1765.

10. L. Tong, Q. Wei, A. Wei, and J.-X. Cheng, Photochem. Photobiol., 2009, 85, 21.

11. H. Wang, D. W. Brandl, F. Le, P. Nordlander, and N. J. Halas, Nano Lett., 2006, 6, 827.

12. E. M. Larsson, J. Alegret, M. Käll, and D. S. Sutherland, Nano Lett., 2007, 7, 1256.

13. S. E. Skrabalak, J. Chen, L. Au, X. Lu, X. Li, and Y. Xia, Adv. Mater., 2007, 19, 3177.

14. Y. Sun, B. Mayers, and Y. Xia, Adv. Mater., 2003, 15, 641.

15. S. J. Oldenburg, R. D. Averitt, S. L. Westcott, and N. J. Halas, Chem. Phys. Lett., 1998, 288, 243.

16. X. Huang, P. K. Jain, I. H. El-Sayed, and M. A. El-Sayed, Photochem. Photobiol., 2006, 82, 412.

17. X. Huang, P. Jain, I. El-Sayed, and M. El-Sayed, Lasers Med. Sci., 2008, 23, 217.

18. M. Brust and C. J. Kiely, Colloids Surf. Physicochem. Eng. Asp., 2002, 202, 175.

19. A. I. Abdelrahman, A. M. Mohammad, T. Okajima, and T. Ohsaka, $J$. Phys. Chem. B, 2006, 110, 2798.

20. S. K. Ghosh and T. Pal, Chem. Rev., 2007, 107, 4797.

21. C. Y. Lau, H. Duan, F. Wang, C. B. He, H. Y. Low, and J. K. W. Yang, Langmuir, 2011, 27, 3355.
22. J. Paczesny, M. Wojcik, K. Sozanski, K. Nikiforov, C. Tschierske, A. Lehmann, E. Gorecka, J. Mieczkowski, and R. Holyst, J. Phys. Chem. C, 2013, 117, 24056.

23. Y. Ofir, B. Samanta, and V. M. Rotello, Chem. Soc. Rev., 2008, 37, 1814.

24. Z. Deng, Y. Tian, S.-H. Lee, A. E. Ribbe, and C. Mao, Angew. Chem., 2005, 117, 3648.

25. L. Ding, C. Hao, Y. Xue, and H. Ju, Biomacromolecules, 2007, 8, 1341.

26. C. Shan, H. Yang, D. Han, Q. Zhang, A. Ivaska, and L. Niu, Biosens. Bioelectron., 2010, 25, 1070.

27. M. Tuerk, U. Tamer, E. Alver, H. Ciftci, A. U. Metin, and S. Karahan, Artif. Cells Nanomedicine Biotechnol., 2013, 41, 395.

28. W. Shenton, S. A. Davis, and S. Mann, Adv. Mater., 1999, 11, 449.

29. K. Aslan, C. C. Luhrs, and V. H. Pérez-Luna, J. Phys. Chem. B, 2004, 108, 15631.

30. S. Srivastava, A. Verma, B. L. Frankamp, and V. M. Rotello, Adv. Mater., 2005, 17, 617.

31. J.-J. Zhang, M.-M. Gu, T.-T. Zheng, and J.-J. Zhu, Anal Chem, 2009, 81, 6641.

32. M. Neupane, S. Lee, I. Park, M. Lee, T. Bae, Y. Kuboki, M. Uo, and F. Watari, J. Nanoparticle Res., 2011, 13, 491.

33. T. Coradin, S. Bah, and J. Livage, Colloids Surf. B Biointerfaces, 2004, 35, 53.

34. Z. Zou, D. He, X. He, K. Wang, X. Yang, Z. Qing, and Q. Zhou, Langmuir, 2013, 29, 12804.

35. J. Allouche, M. Boissiere, C. Helary, J. Livage, and T. Coradin, J. Mater. Chem., 2006, 16, 3120.

36. Y. Liu, X. Liu, and X. Wang, Nanoscale Res. Lett., 2010, 6, 1.

37. V. Vongsavat, B. M. Vittur, W. W. Bryan, J.-H. Kim, and T. R. Lee, ACS Appl Mater Interfaces, 2011, 3, 3616.

38. S. Soulé, J. Allouche, J.-C. Dupin, and H. Martinez, Microporous Mesoporous Mater., 2013, 171, 72.

39. W. Stöber, A. Fink, and E. Bohn, J. Colloid Interface Sci., 1968, 26, 62.

40. G. Beamson and D. Briggs, High Resolution XPS of Organic Polymers: The Scienta ESCA300 Database, Wiley, 1992.

41. C. D. Wagner, W. M. Riggs, L. E. Davis, J. F. Moulder, and G. E. Muilenberg, Perkin-Elmer Eden Prairie MN, 1977.

42. A. Zwijnenburg, A. Goossens, W. G. Sloof, M. W. J. Crajé, A. M. van der Kraan, L. Jos de Jongh, M. Makkee, and J. A. Moulijn, J. Phys. Chem. B, 2002, 106, 9853.

43. H. Bao, T. Bihr, A.-S. Smith, and R. N. Klupp Taylor, Nanoscale, 2014, 6, 3954.

44. S. L. Westcott, S. J. Oldenburg, T. R. Lee, and N. J. Halas, Chem. Phys. Lett., 1999, 300, 651.

45. G. Mie, Ann Phys Leipz., 1908, 25, 377. 